\title{
O FATO SOCIAL TOTAL BRASILEIRO: UMA PERSPECTIVA EINOGRÁFICA SOBRE A RECEPC̄̃̃O PÚBLICA DA COPA DO MUNDO NO BRASIL
}

\author{
Édison Gastaldo* \\ Universidade Federal Rural do Rio de Janeiro - Brasil
}

Resumo: Este trabalho apresenta resultados de investigações etnográficas realizadas durante as Copas do Mundo de 2006 e 2010, em diferentes cidades brasileiras. As pesquisas de campo e gravação das imagens e vídeo foram realizadas por uma ampla equipe de pesquisadores de diferentes instituições, e resultaram em dois vídeos etnográficos: Ritos da nação (2007) $e$ Uma tarde de junho no país do futebol (2010). Neste artigo, utilizo dados dessas duas pesquisas para explorar a noção maussiana de "fato social total" tal como se manifesta no momento ritualizado da recepção pública do "jogo do Brasil" durante uma Copa do Mundo, bem como algumas relações entre esses fenômenos interacionais e os campos da economia, da política e da midiatização.

Palavras-chave: Copa do Mundo, fato social total, futebol, interação social.

\begin{abstract}
This paper presents results of two ethnographic studies held during the FIFA World Cup Finals in 2006 and 2010, in different Brazilian cities. Ethnographic fieldwork and video recordings were done by a team of researchers from several Brazilian Universitues, and resulted in two ethnographic videos, Ritos da nação (2007) and Uma tarde de junho no país do futebol (2010). In this paper, I analyze some data of these researches in order to explore the Maussian notion of "total social fact" as it manifests itself on the ritualized situation of common watching to the Brazilian team 's World Cup Finals match, as well as some relations between these interactional phenomena and the fields of economy, politics and mass-media.
\end{abstract}

Keywords: soccer, social interaction, total social fact, World Cup.

* Bolsista do Conselho Nacional de Desenvolvimento Científico e Tecnológico (CNPq).

Horizontes Antropológicos, Porto Alegre, ano 19, n. 40, p. 185-200, jul./dez. 2013 


\section{Introduç̃o}

A Copa do Mundo de Futebol da FIFA está entre os eventos globais de maior expressão contemporânea em termos econômicos, simbólicos e políticos. Ao longo do século XX, a FIFA e seus dirigentes souberam como construir globalmente esse evento, que, com a força inercial que toda tradição (ainda que inventada) possui, vem se consolidando no século XXI como um poderoso instrumento de competição simbólica entre nações, uma "máquina cultural", como Alabarces (2002) assinala. Na antropologia brasileira, a importância social e simbólica da Copa do Mundo e sua relação com a identidade nacional vem sendo destacada desde os anos 1980 em diferentes perspectivas, na obra de vários pesquisadores, como Guedes (1998), Rial (2003), Damo (2011) e Helal (2002), entre outros. ${ }^{1}$

Além do valor simbólico internacionalmente reconhecido de uma Copa do Mundo, articula-se a esse megaevento um poderoso investimento financeiro. Uma boa parte dos recursos envolvidos na produção e consumo de um megaevento se relaciona à sua produção midiática. Os direitos de transmissão de uma Copa do Mundo são disputados por corporações de mídia de todo o mundo, a um custo de centenas de milhares de dólares por emissora. Segundo estimativa do Banco Merril Lynch (Moysés, 2010), a FIFA teria obtido cerca de 3,3 bilhões de dólares de faturamento pela Copa do Mundo da África do Sul, em 2010.

O caráter supranacional de uma entidade como a FIFA, associado às dimensões econômicas e simbólicas do evento, promovem relações nem sempre pacíficas com o campo da política: a rusga entre o ministro dos Esportes Aldo Rebelo e o secretário da FIFA Jérôme Valcke em março de 2012 é um bom exemplo. Para além das declarações nos jornais, por vezes exceções à legislação precisam ser criadas para acomodar os múltiplos interesses econômicos em jogo, como é o caso da liberação provisória para venda de bebida alcoólica nos estádios da copa, mas somente de uma única marca de cerveja autorizada para venda, a patrocinadora da FIFA. ${ }^{2}$

\footnotetext{
Sobre a constituição histórica do campo acadêmico dos estudos sociais do esporte no Brasil, ver Gastaldo (2010).

2 Esse tipo de "estratégia de marketing" monopolista não ocorre só no Brasil. Como assinalei em outro artigo (Gastaldo, 2001a), durante a Olimpíada de Sydney (2000), por exemplo, os seguranças dos estádios foram instruídos a revistar os torcedores à procura de armas, bombas ou latas de Pepsi.
}

Horizontes Antropológicos, Porto Alegre, ano 19, n. 40, p. 185-200, jul./dez. 2013 
Assim, essa complexa articulação entre política, economia, competição, poder simbólico e identidade nacional envolvida em uma Copa do Mundo permite que a comparemos, como um exercício teórico, com a noção de "fato social total", tal como apresentada por Marcel Mauss (2003), no célebre Ensaio sobre a dádiva, de 1925. Neste artigo, gostaria de pensar o megaevento em microperspectiva, isto é, compreendê-lo a partir do ponto de vista das pessoas para quem a Copa do Mundo se apresenta como uma festa, e que se reúnem em locais públicos em grandes grupos, de centenas ou milhares de pessoas, para assistir coletivamente a este espetáculo raro: um jogo da seleção brasileira na Copa do Mundo.

\section{Notas sobre método}

Os dados de campo para esta pesquisa foram coletados durante duas experiências etnográficas realizadas em diversas cidades brasileiras, durante as Copas de 2006 e 2010. A primeira delas, o projeto "Ritos da nação", realizado durante a Copa do Mundo de 2006, buscou realizar um levantamento etnográfico multissituado, com observação participante e gravação em vídeo de situações de recepção coletiva dos jogos da seleção brasileira na Copa do Mundo. Foram realizadas gravações em Goiânia, Porto Alegre, Campinas, Belo Horizonte, Caxias do Sul e Vale do Sinos. Na ocasião, um dos pesquisadores chegou a fazer gravações no Rio de Janeiro, mas infelizmente seus registros foram extraviados e não puderam ser incluídos no projeto. As etapas e desdobramentos deste projeto foram discutidos detalhadamente em outro artigo (Gastaldo, 2009). O vídeo Ritos da nação (2007) encontra-se disponível no YouTube. ${ }^{3}$

O segundo projeto, intitulado "Uma tarde de junho no país do futebol", apesar de não estar diretamente vinculado ao primeiro, de certa forma lhe dá seguimento. Nele, foi realizada uma etnografia de situações de recepção pública dos jogos do Brasil na Copa do Mundo de 2010, mas exclusivamente na cidade do Rio de Janeiro. O vídeo resultante (Uma tarde de junho no país do futebol, 2010) também está disponível no YouTube. ${ }^{4}$

\footnotetext{
3 Ver http://www.youtube.com/watch?v=dbifw2RE2gw.

4 Ver http://www.youtube.com/watch?v=y6d2784H-PQ.
} 
Foram realizadas filmagens, observações e entrevistas em diversos locais públicos de exibição dos jogos, desde bares e restaurantes com algumas dezenas de torcedores até grandes concentrações de milhares de pessoas, como a arena "FIFA Fan Fest", montada nas areias de Copacabana ou o "Estádio Alzirão", na Tijuca, uma grande avenida que é interditada desde 1978 para exibir os jogos em um telão, e que hoje concentra mais de 30.000 torcedores por jogo a cada Copa do Mundo.

A ênfase das duas pesquisas estava nos processos de interação social entre os torcedores, ou seja, nos modos pelos quais, intersubjetivamente, a situação "jogo do Brasil" e seus múltiplos significados emergiam in situ. A análise do material coletado em campo, com mais de 20 horas de gravações digitais, entrevistas e notas de diários de campo, compõe uma rica fonte de dados sobre o cotidiano brasileiro durante uma Copa do Mundo.

\section{Sobre o fato social total brasileiro}

A noção de "fato social total" (ou "fenômeno social total", na tradução brasileira) foi inicialmente formulada por Marcel Mauss no célebre Ensaio sobre a dádiva, publicado originalmente em 1925. Trata-se de uma noção central do pensamento maussiano, e que é um desdobramento da noção anterior de "fato social", tal como apresentada por Émile Durkheim (2006) em As regras do método sociológico, de $1895 .{ }^{5}$ Em seu artigo, Mauss apresenta a noção de fato social total nos seguintes termos:

Existe aí [nas sociedades arcaicas] um enorme conjunto de fatos. E fatos que são muito complexos. Neles, tudo se mistura, tudo o que constitui a vida propriamente social das sociedades que precederam as nossas - até às da proto-história. Nesses fenômenos sociais "totais", como nos propomos chamá-los, exprimem-se, de uma só vez, as mais diversas instituições: religiosas, jurídicas e morais - estas sendo políticas e familiares ao mesmo tempo -; econômicas - estas supondo formas particulares da produção e do consumo, ou melhor, do fornecimento e da distribuição -; sem contar os fenômenos estéticos em que resultam estes fatos e os fenômenos morfológicos que essas instituições manifestam. (Mauss, 2003, p. 187).

5 Sobre a epistemologia da passagem da noção de fato social em Durkheim à de fato social total em Mauss, ver Tarot (1996). 
A noção de Mauss é, como aponta Kasuga (2009), tanto misteriosa quanto prolífica em desdobramentos teóricos. Ela está na base do desenvolvimento de ideias bastante distintas, como o estruturalismo lévi-straussiano, a sociologia da interação de Erving Goffman e a teoria ator-rede de Bruno Latour.

Segundo Alexander Gofman (1998), a noção de fato social total, apesar de central na obra de Mauss, foi relativamente pouco teorizada pelo próprio autor, e as interpretações dos trechos em que ele alude a essa noção permitem uma variedade de leituras. Assim, encontramos na literatura antropológica interpretações muito diferentes sobre o que possa ser considerado fato social total e com que finalidade analítica essa noção possa ser empregada. É célebre nesse sentido a divergência entre as interpretações da noção de fato social total por Georges Gurvitch e Claude Lévi-Strauss - sobre esse tema, a principal referência é Cazeneuve (1968), mas ver também Dubar (1969), Oliveira (1979) e Sigaud (1999).

Como comenta Gofman (1998, p. 65): "In contrast with many other similar cases, the ambiguity of this concept [total social fact] does not derive from theoretical construction, but from theoretical misconstruction; in other words, from Mauss' refusal to theorize." Para compreender a noção de fato social total, diz ele, é preciso compreender os sentidos do termo "total" ao tempo de Mauss. A ideia de "totalidade" estava bastante presente tanto na obra de Marcel Mauss (como nos termos "sistema de prestações totais" ou "homem total") como no Zeitgeist dos anos 1920, nas ciências sociais e na psicologia (como um bom exemplo de abordagem "total" que se destacava nesse período, se pode citar a Gestaltpsychologie 6 ).

Assim, em Mauss, partir da ideia de "totalidade" implicada na noção de fato social total permite sustentar, segundo Gofman (1998), pelo menos duas acepções deste termo. Para ele, em um primeiro sentido, mais geral, o termo reflete o desejo de Mauss de tratar os fatos sociais em perspectiva "total", isto é, considerando-os como "síntese de múltiplas determinações", para usar a expressão de Claude Dubar (1969). Nesse sentido, todos os fatos sociais seriam passíveis de serem abordados como fenômenos "totais", isto é, considerados do ponto de vista de suas múltiplas conexões a um sistema social mais amplo. Para Gofman (1998, p. 67, grifo do autor, tradução minha), essa

6 Curiosamente, Gofman destaca que, na tradução alemã do Ensaio sobre a dádiva, o termo escolhido para, no subtítulo, traduzir forme, ao invés de Form, foi justamente Gestalt.

Horizontes Antropológicos, Porto Alegre, ano 19, n. 40, p. 185-200, jul./dez. 2013 
primeira acepção é acima de tudo epistemológica e metodológica, consistindo em "estudar todos os fatos sociais como totais".

$\mathrm{Na}$ segunda acepção, mais objetiva, Mauss considera os fatos sociais totais como

specific ontological entities, which are sui generis (to speak in a Durkheimian vein) and distinct from other social facts. In this second sense, these total facts, as he sees them, are phenomena which penetrate every aspect of the concrete social system; they concentrate and constitute its focus, they are the constitutive elements, the generators and motors of the system: 'In certain cases, they involve the totality of society and its institutions ... and in other cases only a very large number of institutions.' One can say that these are 'total social facts' in the true sense of the term. (Gofman, 1998, p. 67, grifo do autor). ${ }^{7}$

Acredito que estabelecer claramente essa distinção entre os diferentes sentidos do termo ajuda a evitar uma série de confusões conceituais subsequentes.

Partindo desse sentido mais estrito do termo, do fato social como entidade ontológica específica, como evento que afeta globalmente uma sociedade, gostaria de destacar algumas coisas. Em primeiro lugar, para Mauss, seu conceito descreve uma espécie de fato social que ocorre em sociedades "arcaicas" ou "primitivas". Assim, acredito que seja necessária sempre uma mediação considerável ao empregarmos esse conceito a um fenômeno global como uma Copa do Mundo.

Em segundo lugar, destacaria o caráter lúdico e competitivo associado aos fatos sociais totais maussianos - a ênfase maussiana no aspecto agonístico dos fatos sociais totais foi bem desenvolvida por Lygia Sigaud (1999). Embora sua definição canônica não destaque explicitamente esse aspecto, os dois principais exemplos de fato social total apresentados por Mauss (o potlatch do noroeste norte-americano e o kula melanésio) estão associados a formas lúdicas e competitivas, a demonstrações de superioridade vitoriosa e a uma série de disputas e competições paralelas aos eventos principais, tanto entre os "grandes homens" quanto entre membros comuns dos grupos em competição.

7 Os últimos dois trechos são citações do próprio Mauss (1990) na versão inglesa The gift: form and reason for exchange in archaic societies. 
Assim, embora deva ser usada certa cautela ao empregar essa noção tão fora de seu contexto original, acredito que, no Brasil, a participação da seleção brasileira em uma Copa do Mundo (evento que pode ocorrer em qualquer parte do mundo) possa ser considerada um fato social total. Mais do que isso. Uma vez que nesse fato social total específico se emblematizam, ritualizam, dramatizam e negociam significados profundos acerca da identidade nacional brasileira, eu diria se tratar do "fato social total brasileiro" por excelência. Explico a ênfase: outros fatos sociais totais ocorrem regularmente no Brasil - mas não apenas não se restringem somente ao Brasil quanto não expressam ou ritualizam a simbólica da "brasilidade", em ritos públicos e privados. Ou seja, fatos sociais totais (na segunda acepção) de extraordinária importância na sociedade brasileira como o Natal ou o réveillon, por exemplo, mobilizam múltiplos campos sociais e elementos simbólicos entrelaçados, mas não apresentam o vínculo forte com a ideia de "nação brasileira" que as ritualizações ocorrentes durante as partidas da seleção brasileira em Copas do Mundo trazem a cada quatro anos. ${ }^{8}$ A força simbólica da ideia dos "90 milhões em ação" (em 1970) expressa mais clara e profundamente do que qualquer outro fato social total (em qualquer sentido do termo), a dimensão simbólica do pertencimento nacional no Brasil. Daí a ênfase na ideia de que a participação da seleção brasileira em uma Copa do Mundo seja "o" fato social total brasileiro.

Uma dimensão importante da diferença entre o que Mauss denomina sociedades "arcaicas" e nossas sociedades "complexas" é de ordem demográfica. Sociedades do primeiro tipo são frequentemente compostas por algumas centenas ou milhares de indivíduos, enquanto uma sociedade nacional como o Brasil - nosso caso específico, afinal - abriga cerca de 200 milhões de indivíduos de diferentes origens étnicas, regionais, educacionais, financeiras, urbanas, etárias, etc. Ou seja, a mobilização de toda uma sociedade para a realização de um evento "total" é muito mais simples quando a produção desse evento envolve algumas centenas ou milhares de pessoas, habitantes de uma

\footnotetext{
Talvez o Carnaval seja o fato social total regular que mais expresse elementos de uma simbólica da "brasilidade", mas mais focada na cultura popular do samba como elemento de pertencimento, e evidenciando antes tensões internas de uma sociedade estratificada racial e economicamente - ver, nesse sentido, DaMatta (1979), Goldwasser (1975) e Rodrigues (1984), entre muitos outros - e sem a dimensão ferozmente competitiva de uma Copa do Mundo, em que só podemos ser "nós" derrotando a "eles", os outros, os estrangeiros, situação liminar em que vivemos simbólica e contrastivamente a plenitude da experiência de "ser brasileiro".
}

Horizontes Antropológicos, Porto Alegre, ano 19, n. 40, p. 185-200, jul./dez. 2013 
mesma região, caso do kula e do potlatch. No caso brasileiro, muito poucos eventos produzem algum efeito de totalidade. Boa parte deles ocorre anualmente e está de alguma maneira relacionada aos ciclos religiosos católicos (Carnaval, Páscoa, São João, Natal, por exemplo).

Uma Copa do Mundo, entretanto, possui algumas distinções importantes. A começar por sua periodicidade. A periodicidade quadrienal faz do tempo da copa um evento extraordinário, que suplanta a lógica rotineira do ciclo anual. Além disso, a Copa do Mundo é um evento competitivo, não é somente uma festa; pode-se ganhar ou perder, há muita coisa em jogo, e esse fator domina completamente os sentidos produzidos sobre o evento. Por fim, em uma Copa do Mundo a seleção brasileira sempre é apontada como uma das favoritas ao título. Ou seja, embora se trate de uma competição dificílima, trata-se de um jogo no qual os jogadores brasileiros têm sempre condição de vencer (mais do que isso, existe uma expectativa unânime de que isso ocorrerá). Acrescente-se a isso a midiatização da sociedade e a possibilidade técnica de transmitir as partidas ao vivo pela televisão para todo o território nacional e teremos alguns bons vetores para a compreensão desse fenômeno total.

Em outro artigo (Gastaldo, 2009) comentei alguns efeitos da realização de uma Copa do Mundo sobre a audiência midiática no Brasil. Toda vez que a seleção brasileira entra em campo em uma copa, ocorre uma extraordinária concentração de audiência, da ordem de 95\% a 98\% dos televisores ligados, permitindo uma estimativa da ordem de 100 a 120 milhões de telespectadores por jogo. Se acrescentarmos a esses números a audiência de rádio, internet e outros meios, teremos um raro momento "total" da sociedade brasileira, um momento extremamente ritualizado e no qual se dramatiza o "ser brasileiro", expresso em sua dimensão mais competitiva, construída na tensão com a alteridade do "adversário". Interpretar os sentidos envolvidos nessa rara situação total de sociabilidade brasileira é nossa proposta analítica neste trabalho.

\section{Ritos da nação: o Brasil na Copa do Mundo em perspectiva etnográfica}

Do ponto de vista das pessoas envolvidas com a recepção dos jogos da seleção brasileira, o período da Copa do Mundo se caracteriza como um período em que se ritualiza a lógica do jogo. Não apenas do futebol, embora seja a referência lúdica mais óbvia. Vários outros tipos de jogo pautam este período. 
Se utilizarmos a tipificação dos jogos proposta por Roger Caillois (1990) em Os jogos e os homens, veremos que os quatro tipos básicos de jogo estão simultaneamente presentes durante esse período. Os jogos do tipo agôn, os jogos de competição, se manifestam no próprio campo de jogo, com a seleção brasileira enfrentando uma equipe de outro país, evento que constitui o epicentro do fenômeno total. A metonímia segundo a qual os jogadores da seleção brasileira são considerados "o Brasil" é uma constante nesse período, tanto no discurso midiático quanto na fala dos/as informantes.

Os jogos do tipo alea, ou jogos de azar, estão presentes por toda a parte, sob a forma de bolões, loterias, sorteios e apostas que ocorrem paralelamente ao correr da competição, utilizando os resultados das partidas e da combinatória das chaves de classificação. Durante o trabalho de campo, diversos informantes relataram participar em todas as Copas do Mundo dessas apostas coletivas, ou "loteria entre amigos". O campo das mídias aproveita essa excelente oportunidade de faturamento; emissoras de televisão oferecem sorteios de prêmios ao longo da programação, jornais sorteiam camisetas oficiais da seleção brasileira, etc. Ou seja, pode-se "jogar" de muitas formas durante uma Copa do Mundo. Sobre esse tema, ver Gastaldo (2001b).

Jogos do tipo mimicry, ou jogos de representação, fazem parte inextricável da conduta dos/as participantes durante os jogos, sob a forma de "fantasias" verde-amarelas, composta com adereços carnavalescos como perucas, óculos, camisetas com as mais diversas estampas, vuvuzelas, etc., além de pinturas corporais e faciais. Esse ponto é praticamente uma unanimidade, são raras as pessoas que assistem aos jogos em locais públicos e que, de alguma maneira, não se "produziram" com as cores nacionais.

Uma exceção a ser mencionada é a utilização deliberada do uniforme de um clube, não da seleção brasileira. Trata-se de uma distinção que muitos torcedores de futebol clubístico buscam com relação a uma categoria depreciativa que emerge nessa situação, definida como "torcedor/a de Copa do Mundo". Em entrevista, os torcedores de futebol clubístico desprezam os/as "torcedores de Copa do Mundo" por sua falta de expertise futebolística. Estes torcedores frequentemente reportam se importar mais (sofrer, emocionar-se, envolver-se, etc.) com o seu clube do que com a seleção brasileira, exibindo uma atitude de superioridade blasé para com a multidão de "torcedores de copa" (categoria êmica, evidenciando a naïvité daqueles), evidentemente em maioria na situação e com quem não querem ser confundidos.

Horizontes Antropológicos, Porto Alegre, ano 19, n. 40, p. 185-200, jul./dez. 2013 
Por fim, os jogos do tipo ilinx, ou jogos de vertigem, se manifestam no elevado consumo de bebidas alcoólicas que acompanha a assistência aos jogos e na comemoração coletiva na hora do gol. Momento de "descontrole controlado," manifesto pela livre expressão sonora: buzinas, gritos, fogos de artifício e vuvuzelas são a expressão dessa ausência de limites ritualmente situada. Um interessante dado de mercado acompanha a dimensão econômica desse consumo ritualizado de bebidas alcoólicas: nos anos em que há Copa do Mundo, o mês de junho apresenta maior consumo de cerveja, em todo o Brasil, do que o mês de fevereiro, com um aumento global de 10\% (Lima, 2010).

Nessa situação liminar de hiper-ritualização (Goffman, 1979) do vínculo entre futebol e identidade nacional, considero importante destacar sua midiatização como parte essencial do fenômeno. Pensando cada situação analisada como parte de um gigantesco ambiente de mídia, em que as imagens projetadas nos telões dominam e definem a situação, é interessante apresentar algumas inferências sobre a relação dos participantes com a mídia e, a seguir, sobre os usos sociais dos símbolos da nacionalidade.

A situação pesquisada pode ser definida nos termos de Erving Goffman (1963) como uma "interação focada", fenômeno que ocorre quando um conjunto de pessoas sustenta efetivamente um foco único de atenção visual e cognitiva em um mesmo ambiente. Nos ambientes pesquisados, a atenção de todos os participantes se volta para as telas. Uma única tela tende a criar um "cone" de espectadores à sua frente; vários telões, dispostos em semicírculo (como em shopping centers, praças, parques ou mercados públicos, por exemplo) criam, pela justaposição de espectadores, uma perda de contornos nítidos, aglomerando, por vezes, vários milhares de pessoas. $\mathrm{O}$ arranjo é de tal ordem que qualquer participante pode, sem se mover, assistir ao jogo em diversas telas. Assim, embora o olhar dos participantes indique variadas direções, o fenômeno que cria aquela situação é sempre o mesmo, facilmente identificável pela atitude corporal similar dos torcedores, evidenciada, por exemplo, no momento de um gol.

Outro ponto importante a destacar é o quanto a adesão dos/as torcedores/as à seleção brasileira é altamente dependente do desempenho do próprio time. Antes de cada jogo, durante o período que os torcedores/as chamam de "concentração" (momento de atenção desfocada, de beber as primeiras doses 
e encontrar os/as amigos/as que combinaram assistir ao jogo juntos/as) a expectativa inicial é invariavelmente confiante, a crença de que a seleção brasileira vencerá todos seus jogos por goleada e terminará a copa como campeã invicta. Porém, uma vez começado o jogo, a atuação da equipe nacional pode rapidamente dissipar essa expectativa, sendo frequentes as manifestações de desagrado, vaias e ironia. Na partida contra o Japão, na primeira fase da Copa do Mundo de 2006, por exemplo, uma partida considerada fácil (e que acabou sendo vencida pelo Brasil por 4 x 1), o primeiro gol do jogo foi do Japão, no final do primeiro tempo: em diversos locais, os torcedores aplaudiram de pé, em uma irônica homenagem ao fraco adversário.

Com relação ao uso social do espaço, cabe destacar o que Goffman (1959) denomina "determinismo da situação", isto é, a tendência a que cada diferente situação social "determine" em boa parte a conduta dos/as participantes (na medida em que, em cada situação social, certas ações são limitadas ou proscritas e outras, estimuladas). A mesma situação em termos formais - exibição pública de jogos da seleção brasileira durante uma Copa do Mundo - pode apresentar conduções e desfechos muito distintos. Assistir ao jogo em bares, por exemplo, onde há facilidade no consumo de bebidas alcoólicas - basta pedi-las ao garçom - torna essa situação bastante mais barulhenta e emocionalmente exagerada do que, por exemplo, assistir ao jogo em auditórios universitários ou empresas, onde a bebida alcoólica não é permitida e o enquadre de situação profissional/acadêmica não é de todo abolido. Em praças públicas, por outro lado, onde o consumo de bebidas depende da passagem de algum eventual vendedor ambulante, esse fator não chega a afetar tanto a performance dos/as participantes quanto a atitude de "desatenção civil" (Goffman, 1971) aos circundantes, característica da conduta em áreas públicas.

No que diz respeito aos usos rituais de símbolos de identidade nacional pelos/as participantes, o jogo da seleção brasileira na Copa do Mundo é um momento altamente cercado de consumos ritualizados. A peça de vestuário mais óbvia - a camiseta da seleção - é vendida em versões "não oficiais" nas principais vias de acesso a locais de concentração de torcedores, penduradas em longos varais estendidos entre placas de trânsito ou postes de iluminação. As cores verde e amarelo parecem ser um dos mais poderosos operadores simbólicos da nacionalidade: em todos os settings pesquisados a grande maioria 
dos torcedores usava alguma peça de roupa ou detalhe nas cores nacionais, seja um chapéu, lenço, fita, pulseira, etc. A atitude com relação ao hino nacional representou de fato uma surpresa: nossa expectativa era a de que a música que expressa oficialmente os valores nacionais fosse ser cantada a plenos pulmões. Entretanto, o padrão apresentado foi da mais completa indiferença. $\mathrm{Na}$ única situação em que o hino foi efetivamente cantado pelos torcedores, em Campinas - imagens que aparecem na sequência de abertura do vídeo Ritos da nação - percebe-se claramente uma "apresentação" para os cinegrafistas: os olhares dos participantes dirigem-se diretamente à lente, e acompanham o movimento da câmara, podendo ser interpretados mais como uma performance destes torcedores para a câmara do que uma manifestação de orgulho cívico.

É intrigante que tanto a bandeira quanto o hino nacional - símbolos nacionais oficiais, relacionados com o Estado - tenham sido praticamente ignorados, enquanto que a camisa da seleção e o futebol brasileiro - símbolos "não oficiais" da nação - parecem cativar muito mais atenção por parte dos torcedores. Talvez o vínculo - que já foi bastante forte - entre esportes, identidade nacional e o Estado, sintetizado na expressão "uso político dos esportes", esteja mesmo se enfraquecendo - como haviam antecipado Helal e Soares (2003). A vinculação a valores nacionais, nesse sentido, poderia ser vista mais como uma questão de lazer privado/individual do que de engajamento político/coletivo.

\section{Para concluir}

A investigação de um raro "fato social total" em uma sociedade moderna e complexa é um desafio à pesquisa antropológica, que mostra trilhas promissoras para compreendermos os meandros do que seja "identidade nacional" neste início de século XXI. A riqueza dos dados coletados em uma ocasião tão rara aponta para novas reflexões sobre a recepção de mídia em condições especiais, uma situação em que se ritualizam as dimensões sociais do futebol e da identidade nacional no Brasil, uma cultura nacional em processo.

A utilização de múltiplos suportes de coleta de dados - gravações em vídeo, entrevistas e observação participante - e de pesquisa etnográfica multissituada permitiu abordar, com densidade, variados elementos dessa situação total, permitindo, por assim dizer, uma microperspectiva de um macroevento.

Horizontes Antropológicos, Porto Alegre, ano 19, n. 40, p. 185-200, jul./dez. 2013 
Como veiculação de resultados de pesquisa, devo acrescentar que a produção de documentários etnográficos a partir das gravações de vídeo feitas em campo mostrou-se muito satisfatória para a divulgação da pesquisa junto a um público muito maior do que aquele restrito ao universo acadêmico.

Tendo em vista que nos próximos anos o Brasil será sede de dois megaeventos esportivos, acredito que compreender as lógicas simbólicas da identidade nacional envolvidas nesses eventos totais é um caminho promissor para entender o futebol como fato social no Brasil, saber onde reside e em que consiste nosso vínculo afetivo com essa prática.

\section{Referências}

ALABARCES, P. Fútbol y patria. Buenos Sires: Prometeo Libros, 2002.

CAILLOIS, R. Os jogos e os homens. Lisboa: Cotovia, 1990.

CAZENEUVE, J. Sociologie de Marcel Mauss. Paris: Presses Universitaires de France, 1968.

DAMATTA, R. Carnavais, malandros e heróis: para uma sociologia do dilema brasileiro. Rio de Janeiro: Rocco, 1979.

DAMO, A. S. Produção e consumo de megaeventos esportivos - apontamentos em perspectiva antropológica. Comunicação, Mídia e Consumo, São Paulo, v. 8, p. 67-92, 2011.

DUBAR, C. La méthode de Marcel Mauss. Revue Française de Sociologie, v. 10, n. 4 , p. 515-521, 1969.

DURKHEIM, E. As regras do método sociológico. São Paulo: Martins Fontes, 2006.

GASTALDO, E. Publicidade, esporte e nacionalidade na Grã-Bretanha: representações sociais na publicidade dos Jogos Olímpicos de Sydney. Revista Fronteiras, São Leopoldo, v. 3, n. 2, p. 95-112, 2001 a. 
GASTALDO, E. Um Tempo para Jogar: o "ser brasileiro" na publicidade da Copa do Mundo de 1998. Revista Campos, v. 1, n. 1, p. 123-146, 2001 b.

GASTALDO, E. O "país do futebol" mediatizado: mídia e Copa do Mundo no Brasil. Sociologias, v. 22, p. 352-369, 2009.

GASTALDO, E. Estudos sociais do esporte: vicissitudes e possibilidades de um campo em formação. Logos, v. 17, p. 7-15, 2010.

GOLDWASSER, M. J. O palácio do samba. Rio de Janeiro: Zahar, 1975.

GOFFMAN, E. The presentation of selfin everyday life. New York: Doubleday Anchor, 1959.

GOFFMAN, E. Behavior in public places. New York: The Free Press, 1963.

GOFFMAN, E. Relations in public. New York: Penguin Books, 1971.

GOFFMAN, E. Gender advertisements. New York: Macmillan, 1979.

GOFMAN, A. A vague but suggestive concept: 'the total social fact'. In: JAMES, W.; ALLEN, N. J. (Org.). Marcel Mauss: a centenary tribute. London: Berghahn Books, 1998. p. 63-70.

GUEDES, S. L. "O salvador da pátria": considerações sobre a imagem do jogador Romário na Copa do Mundo de 1994. In: GUEDES, S. L. O Brasil no campo de futebol. Niterói: EDUFF, 1998. p. 61-78.

HELAL, R. As idealizações de sucesso no imaginário brasileiro: um estudo de caso. In: HELAL, R.; LOVISOLO, H.; SOARES, A. J. (Org.). A invenção do país do futebol. Rio de Janeiro: Mauad, 2002. p. 135-148.

HELAL, R.; SOARES, A. J. O declínio da Pátria de Chuteiras: futebol e identidade nacional na Copa do Mundo de 2002. In: ENCONTRO ANUAL DA COMPÓS, 12., 2003, Recife. Anais... Recife: PPGCOM/Universidade Federal de Pernambuco, 2003. p. 1-15. 
KASUGA, N. Total social fact: structuring, partially connecting, and reassembling. Paper apresentado no seminário "Mauss Vivant", Cerisy-laSalle, 13-20 jun. 2009. Disponível em: <http://www.soc.hit-u.ac.jp/ kasuga/ kasuga01.pdf $>$. Acesso em: 20 dez. 2012.

LIMA, P. S. Copa é como um "mês extra" para fabricantes de cerveja. IstoÉ Dinheiro, São Paulo, 27 maio 2010. Disponível em: $<$ http://www.istoedinheiro. com.br/noticias/24318_COPA+E+COMO+UM+MES+EXTRA+PARA+FA BRICANTES+DE+CERVEJA>. Acesso em: 20 dez. 2012.

MAUSS, M. The gift: form and reason for exchange in archaic societies. London: W. D. Halls, 1990.

MAUSS, M. Ensaio sobre a dádiva. In: MAUSS, M. Sociologia e antropologia. Rio de Janeiro: Cosac \& Naify, 2003. p. 183-314.

MOYSÉS, A. Fifa ganha mais com mundial do que países organizadores. RFI: português, 11 jun. 2010. Disponível em: <http://www.portugues. rfi.fr/copa-2010/20100611-fifa-ganha-mais-com-mundial-do-que-paisesorganizadores-0>. Acesso em: 20 dez. 2012.

OLIVEIRA, R. C. Introdução a uma leitura de Mauss. In: OLIVEIRA, R. C. (Org.). Marcel Mauss. São Paulo, Ática, 1979. p. 7-50.

RIAL, C. S. Futebol e mídia: a retórica televisiva e suas implicações na identidade nacional, de gênero e religiosa. Antropolítica: Revista Contemporânea de Antropologia e Ciência Política, Niterói, v. 14, n. 1, p. 6180, 2003.

RITOS DA NAÇÃO. Roteiro e direção: Édison Gastaldo. São Leopoldo, 2007. DVD.

RODRIGUES, A. Samba negro, espoliação branca. São Paulo: Hucitec, 1984.

SIGAUD, L. As vicissitudes do "Ensaio sobre a Dom". Mana, Rio de Janeiro, v. 5, n. 2, p. 89-123, 1999. 
TAROT, C. Du fait social de Durkheim au fait social total de Mauss: um changement de paradigme? Revue Européenne de Sciences Sociales, t. 34, n. 105, p. 113-144, 1996.

UMA TARDE DE JUNHO NO PAÍS DO FUTEBOL. Direção e roteiro: Édison Gastaldo. Rio de Janeiro, 2010. DVD.

Recebido em: $31 / 12 / 2012$

Aprovado em: 04/06/2013 